\title{
Challenges to EFL Teachers in a Changing Time
}

\author{
Yuyan Jia \\ College of Foreign Languages \\ Dalian University of Science and Technology \\ Dalian, China
}

\author{
Ping Zhao \\ College of Foreign Languages \\ Dalian University of Science and Technology \\ Dalian, China
}

\begin{abstract}
In this changing time, EFL teachers are confronted with different challenges. The competence and roles of them should appropriately respond to these challenges. EFL teachers are suggested to improve their self-growth, knowledge structure, teaching abilities. Meanwhile, governments, society and schools should also play a role in EFL teacher professional development.
\end{abstract}

Keywords-challenges; EFL teachers; competence; roles; countermeasures

\section{INTRODUCTION}

Great changes have taken place with the development of the Internet and Artificial Intelligence (AI) technology. Globalized economy, online learning, online colleges, massive open online courses (MOOC), Micro-lectures, Google Neural Machine Translation (GNMT), robotassisted teaching emerged and began to affect education. EFL teachers, an important part of education, are unavoidably influenced by the challenges in this changing time. The requirements for their competence, roles as well as their self-development are improving. Curtain and Pesola suggest that foreign language teachers today "require a combination of competencies and background that may be unprecedented in the preparation of language teachers". It is necessary and urgent for EFL teachers to put every aspect of the challenges into consideration and take corresponding measures to adapt to the new situations.

\section{Challenges to EFL TEACHERS}

\section{A. Higher Requirements in EFL Teachers' Competence}

In 2004, European Union issued European profile for language teacher education - a frame of reference. In 2002, American Council on the Teaching of Foreign Language (ACTFL), Interstate New Teacher Assessment and Support Consortium (INTASC) and The National Board for Professional Teaching Standards (NBPTS) worked together and released Program Standards for the Preparation of Foreign Language Teachers, Model Standards for Licensing Beginning Foreign Language Teachers, World Languages Other than English Standards for Teachers of Students Ages 3-18. In 2013, 2011 and 2015, they modified the standards respectively to meet the requirements caused by educational changes in the world. Similarly, Australian Federation of Modern Language Teachers Associations (AFMLTA) published Professional Standards for Accomplished
Teaching of Languages and Culture and revised it in 2012. According to these standards, three classifications about present teacher competence are generally included, namely, professional knowledge, professional abilities and professional qualities. Along with the time changing and new challenges, these standards are changing correspondingly for higher demands from various aspects.

1) Professional knowledge: In 2016, Google Company declared the accuracy of its GNMT almost reached human level. In the same year, Sogou Company made similar declaration. Despite the exaggeration of their translation accuracy, the two companies' technology has nearly accomplished the basic and formal reading and translating tasks. The news posted a threat to EFL teachers. Traditionally, EFL teachers were required to own knowledge about the language and its culture. When almost everyone can use an app to communicate with foreigners, to translate formal documents, the current EFL teachers have to acquire more to teach students. They should have a broader sense of knowledge, including language acquisition theories, information technology, pedagogies and so forth besides the basic knowledge structure.

2) Professional abilities: Professional abilities used to mainly refer to EFL teachers' teaching ability and evaluating ability. However, the main focus of EFL teachers has shifted from teaching to learning. EFL teachers put more emphasis on offering their students individualized instructions on autonomous learning. To help students make most use of the foreign language they are learning, EFL teachers should give top priority to maintaining students' interest and motivation of the language learning (Dingfang Shu, 2008), and then create good learning environment for students through a diversity of channels to communicate with each other in E-era. In addition, they should be able to apply modern educational technology to daily teaching and guide students to apply what they have learned to practice. Meanwhile, for high learning and teaching efficacy, reflection and self-evaluation are greatly advocated nowadays.

3) Professional qualities: Teachers are always considered committed gardeners and role models with good virtues for students. Treating students equitably with patience and tolerance, observing professional ethics are what they should do. Apart from these, economic 
globalization and international exchanges make advocating language and cultural diversity, foreign language education as well as global vision indispensable in foreign language teaching. Meanwhile, individual development and professional development, the guidance of values and personality shaping should also be taken into consideration.

\section{B. Changing Roles of EFL Teachers}

1) From an authority to a friend: Students, especially those in Asia, regarded their teachers as authorities. Teachers enjoyed many privileges. It was rare for them to be offended or questioned. But with the widespread of liberal ideas and individualism, teachers have walked down from the altar. They began to treat students in an equal manner and vice versa. Students discuss teaching contents with teachers in class and chat with teachers about their personal life through the internet after class. The relationship between teachers and students is more harmonious. Teachers have been seen as instructors in class and friends in daily life.

2) From a teacher to a participator: Nowadays, teaching and learning activities are shifting from teachercentered process to student-centered process. Teaching is also a process of learning. EFL teachers may act as a learner in and after class. They get involved in class discussion, consult learning strategies with students and provide autonomous learning guidance to students. Thinking in perspective of a learner may give teachers different views on teaching.

3) From a teacher to a learning partner: As Proposition 5 offered by NBPTS puts it teachers are expected to be members of learning communities. Present EFL teachers carry more responsibilities. They are no longer confined to individual career development. They also pay attention to instructional policy, curriculum development and staff development. They collaborate with parents and schools, build partnerships with community groups and businesses for better educational effects.

\section{Higher Needs from Students}

Unlike the students in the past who sat in the classroom waiting for teachers' feeding, today's students are eager to know more, learn more, find more and use more. Chinese scholar and educator Runqing Liu introduced five states of a class: 1) It is at least informative. 2) The information should be facts. 3) Turn the information into systematic knowledge. 4) Combine knowledge with wisdom. 5) If possible, add philosophy to the class. Certainly, it is difficult for EFL teachers to fulfill all the five states in one class. However, making a class informative, practical and attractive is elementary for EFL teachers. Searching and choosing relevant and interesting information is basic for them. In this E-era, most information is accessible to most people. As a result, it is not easy for EFL teachers to search and offer fresh information faster than students. They should always stay abreast of current issues in education and in the world. Also, making the class interesting, keeping most students engaged and focused is more challenging. EFL teachers should understand students' needs and their language proficiency, design different questions for students at different levels and offer individualized instructions to them. In addition, advanced technology has triggered students' desire to learn in a variety of ways. It is unavoidable for EFL teachers to learn to present their teaching and guidance under multi-media and internet environment. Audio and video files, MOOC, Micro-lectures are all useful resources for class teaching and autonomous learning. Try to have the wide application of them is the task of EFL teachers.

\section{Countermeasures Against the Challenges to EFL TEACHERS}

Confronted with so many challenges, both EFL teachers and the governments, the society as well as schools should do something to better fit the improving demands for teachers, teaching and education.

\section{A. EFL Teachers Should Hold the Belief of Lifelong Learning}

The development of science and technology has motivated social development. The social development calls for educational development. EFL teachers play an important role in this fast developing world. They have to equip themselves with appropriate competence for the approaching challenges. To keep pace with the higher requirements in education, they have to update their previous knowledge, abilities, pedagogies and conceptions continuously. Based on this, lifelong learning is essential. Pre-service training and inservice training only are not adequate for EFL teachers' daily teaching and future development. They have to hold the belief of lifelong learning and self-growth, observe their routine teaching and students' learning carefully, watch more classes of other colleagues, learn to find out the rules of foreign language teaching and learning, combine scientific research with practice. As a consequence, it is possible for them to improve their teaching efficacy and keep their own continuous development.

\section{B. EFL Teachers Should Improve Their Competence}

1) Modifying professional knowledge structure: Today's professional knowledge covers not only language knowledge and culture, but also knowledge in other relevant fields, such as pedagogies, second language acquisition theories and educational psychology. Intercultural communicative knowledge and basic knowledge about international trade, international laws as well as international practices also play a significant part in foreign language education. Therefore, it is a wise choice for EFL teachers to broaden their professional knowledge and modify knowledge structure.

2) Improving teaching abilities: The emergence of neural machine translation and robot-assisted teaching has made it urgent for EFL teachers to reconsider these questions: What should I teach? How can I teach effectively? How do I assess a class and my students and my teaching? 
How can I improve my teaching? To begin with, EFL teachers should combine teaching materials with the carefully chosen content obtained from the internet or other resources and set difficult points and key points according to students' learning capability. For the purpose of good preparation, materials should be given to students in advance. Secondly, to offer individualized instructions to students, EFL teachers should design appropriate questions, class activities and assignments for students of diverse levels and give each student chance to get involved. Thirdly, assessing and testing ability is also crucial to EFL teachers. At present, teachers pay more attention to formative evaluation instead of terminal evaluation. When they choose or design a test, they think over the test structure, test content, test timing and test grading, making each test reliable and valid. Fourthly, facing various educational reforms, EFL teachers are expected to take part in the reforms and reflect on their teaching practices, analyze and summarize their teaching for adjustment and improvement of subsequent teaching and learning. In addition, EFL teachers cannot neglect their teaching and scientific research for the fact that the research achievements can promote their teaching in return.

3) Optimizing guidance of autonomous learning: R. Hutchins once said the object of education is to prepare the young to educate themselves throughout their lives. Teaching is not the aim, whereas teaching students to learn on their own is. The time for classroom teaching is limited for most EFL teachers. Therefore, helping students take autonomous learning is the most effective measure to improve teaching effects. Current students are crying for tailored instructions because of their differences on language command, personality, interest, learning objective, learning capacity and learning habit. It is fairly demanding for EFL teachers. In order to realize the objective, they have to make a great deal of preparations. Collecting information, classifying resources, studying learning strategies, setting appropriate methods for each student are what should be done step by step. In the process of choosing optimal learning strategies and maintaining students' autonomous learning, EFL teachers can also ask for help from students themselves, their classmates, parents and schools. Students can collaborate and learn in groups; parents and schools can supervise and support their learning. With the joint efforts from all the people, students may be more likely to persist in autonomous learning and benefit from the learning process.

\section{EFL Teachers Should Integrate Personality Shaping and Values into Teaching}

It is self-evident that teachers have fundamental influence on their students. That is why teachers act as a role model for students. Students who learn foreign languages are inclined to be affected by foreign cultures. Furthermore, in this time, moral sense is declining and mass media along with the internet may easily mislead students. Therefore, EFL teachers should lay emphasis on the penetration of value guidance and personality shaping regardless of students' age differences. In their daily contact with students, they can catch the opportunity to guide students to build universally accepted values and cultivate students' personalities such as self-esteem, cultural confidence, taking responsibilities, observing work ethnics, having global vision and so on. As long as EFL teachers put enough time and energy into searching the point of penetration, they can pick up relevant teaching contents in the topic of each unit, in a text, even in an exercise item. Naturally integrating the values and admirable personalities with teaching may of great benefits to many students in the long run.

\section{Things That Governments, Society and Schools Should Do}

In recent years, EFL teachers have been experiencing pressures from social changes and professional challenges. The pressures have become the main constraints on EFL teacher professional development, namely, the conflict between EFL teachers' heavy workload and limited energy put in academic research; the conflict between unsatisfactory professional development conditions and higher demands from students, schools and society; the lack of ability in doing academic research and the difficulties in doing it (Lian Zhang, 2013). To cope with these constraints, governments, society and schools should work as a whole to create better environment for EFL teacher professional development. To be specific, respecting EFL teachers and improving their social status and welfare is the first step for their professional development. In addition, the three parties need to make plans of regular pre-service training and in-service training programs for EFL teachers. Given the pressures on EFL teachers, establishing some special consulting places to release their pressures is also beneficial to their mental health.

\section{CONCLUSION}

The changing time has brought about new challenges to EFL teachers. They take full responsibilities for educational reforms and talent cultivation. Voluntarily or involuntarily, they have to adjust themselves to the new situations and problems. Collaboration of EFL teachers themselves, schools, society, governments is recommended for EFL teacher professional development. No doubt that the challenges and countermeasures suggested by authors in this paper are not adequate. Detailed and further discussion and research on them should be given.

\section{REFERENCES}

[1] Dingfang Shu, Zhixiang Zhuang, Modern Foreign Language Teaching: Theories, Practices and Motheds, 2nd ed., Shanghai: Shanghai Foreign Language Education Press, 2008, pp.147-153.

[2] Ekaterina M. Kuznetsova, Lubov. V. Mikhaleva, "Professional abilities of foreign language teachers: a pilot survey," J. ProcediaSocial and Behavioral Sciences vol. 200, pp. 278-282, 2015.

[3] Joanna Madalińska-Michalak \& Bünyamin Bavli, "Challenges in teaching English as a foreign language at schools in Poland and Turkey," J. European Journal of Teacher Education, Volume 41, October 2018. 
[4] Mochamad Zein, "Professional development needs of primary EFL teachers: perspectives of teachers and teacher educators," J. Professional Development in Education, Volume 43, pp. 293-313, 2017

[5] Xingguo Ye, "New situations and problems faced by foreign language teachers," J. Foreign Language Teaching and Research, vol. 49, pp. 292-295, March 2017.

[6] Weihe Zhong, Weiwei Wang, "The construction of a competence framework and developmental system of English programs under national critera," J. Foreign Language World, No.6, pp. 4-8, December, 2016.

[7] Lian Zhang, "Constraints on university foreign language teacher professional development and countermeasures: a case study," Foreign Languages in China, vol. 10, pp. 081-088, January 2013.

[8] Qoyyimah, Uswatun, "Inculcating character education through EFL teaching in Indonesian state schools," J. Pedagogies: An International Journal, vol. 11(2), pp. 109-126. 2016.

[9] Yolanda-Mirela Catelly, "The foreign language teacher's roles in response to the knowledge society requirements," J. vol. 11, pp. 127131, 2011.

[10] Lavinia Hulea, "The double role of foreign languages teachers," J. Procedia-Social and Behavioral Sciences vol. 191, pp. 2339-2341, 2015.

[11] B. BELL and J. GILBERT, "Teacher development as professional, personal, and social development," J. Teaching and Teacher Education, vol.10(5), pp.483-497, 1994.

[12] https://www.nbpts.org/ 